\title{
Descrição acústico-articulatória e perceptiva das líquidas do português brasileiro produzidas por crianças com e sem transtorno fonológico
}

\author{
Luciana de Oliveira Pagan-Neves ${ }^{1}$
}

Pagan-Neves LO. Descrição acústico-articulatória e perceptiva das líquidas do português brasileiro produzidas por crianças com e sem transtorno fonológico [tese]. São Paulo: Faculdade de Filosofia, Letras e Ciências Humanas da Universidade de São Paulo; 2008.

O presente trabalho foi dividido em dois estudos. O primeiro deles (Estudo 1) teve como objetivo descrever e comparar as características acústicas das líquidas ///; / / e / / / do português brasileiro enquanto o segundo (Estudo 2) procurou descrever e comparar a percepção auditiva das líquidas apresentadas a juízes. Para isto, foi analisada acusticamente a produção das líquidas $/ 1 / ; /$ / e $/ K /$ realizada por dez crianças sem alterações de fala e linguagem (GC), com idade compreendida entre 5:11 e 9:0 anos, e dez com transtorno fonológico (GTF) e idade entre cinco e doze anos. Após a avaliação fonológica, as crianças dos dois grupos foram solicitadas a repetir três vezes as sílabas /la, li, lu/; /ra, ri, ru/ e /Ka, Кi, Кu/ e as palavras /se'bola/, /'lãma/, /'miKu/, /zaka're/, /Zi'rafa/, /pa' Kasu/. A amostra de fala foi coletada e armazenada no CSL-Computarized Speech Laboratory $4300 \mathrm{~B} / 4500$. Os parâmetros acústicos selecionados para a análise acústica do Estudo 1 foram: valores das frequiências formantes F1, F2 e F3, duração do som-alvo, duração da sílaba contendo o som-alvo, duração do som anterior (quando presente) e do subseqüente, duração da porção estável do som-alvo, valores da transição do som-alvo para a vogal subseqüente (/l/) e duração da transição do som-alvo para a vogal subseqüente (/l/), transição do som-alvo para o som inserido (/// e /K/) e do som-inserido para a vogal subseqüente $(/ \mathrm{r} / \mathrm{e} / K /)$, duração da transição do som-alvo para o som inserido (/ז/ e / / /), slope (medida de velocidade de movimentação dos articuladores). Em seguida à análise dos dados, uma amostra de fala foi selecionada pela pesquisadora para o Estudo 2. Esta amostra foi apresentada a dois grupos de juízes da FMUSP, um composto por alunos do curso de graduação e outro por alunos de pós-graduação, todos fonoaudiólogos, que deveriam realizar um julgamento perceptivo-auditivo das sílabas e palavras. Os dados foram analisados estatisticamente por meio dos testes ANOVA, Teste-t e qui-quadrado (nível de significância adotado de 5\%). Em relação às medidas acústicas, os resultados indicaram que as crianças do GC, de modo geral, foram capazes de produzir as sílabas e palavras solicitadas de maneira mais estável e precisa do que as crianças do GTF. A análise do slope mostrou que o $\mathrm{GC}$ apresentou movimentos mais rápidos $\mathrm{e}$ precisos, do ponto de vista articulatório, quando comparado ao GTF. Há evidências de que o GC utilizou parâmetros acústicos de duração e das frequiências formantes para diferenciar uma líquida da outra, enquanto o GTF utilizou predominantemente a duração como diferenciador. Observando o comportamento acústico-articulatório do GC, verificou-se que a língua apresenta maior movimentação ascendente e descendente durante a produção do /l/ e uma mudança ântero-posterior mais acentuada na produção do /r/. Em relação à análise perceptiva foi possível notar que, apesar do maior número de erros ter sido observado no grupo de juízes da pós-graduação, ambos tiveram mais dificuldade de julgar perceptivamente as sílabas e palavras com a líquida /r/.

Trabalho apresentado à Faculdade de Filosofia, Letras e Ciências Humanas da Universidade de São Paulo - USP - São Paulo (SP), Brasil, para obtenção do título de Doutor em Lingüística e Semiótica Geral sob orientação da Profa. Dra. Haydée Fizsbein Wertzner.

(1) Doutora, Colaboradora do Laboratório de Investigação Fonoaudiológica em Fonologia do Departamento de Fisioterapia, Fonoaudiologia e Terapia Ocupacional da Faculdade de Medicina da Universidade de São Paulo - USP - São Paulo (SP), Brasil.

Endereço para correspondência: Luciana de Oliveira Pagan-Neves. R. Lord Cockrane, 26/152, São Paulo - SP, CEP 04213-000.

E-mail: lucianapagan@ hotmail.com 